Prepared for the U.S. Department of Energy under Contract DE-AC05-76RL01830

\title{
Experimental Design for a Sponge-Wipe Study to Relate the Recovery Efficiency and False Negative Rate to the Concentration of a Bacillus anthracis Surrogate for Six Surface Materials
}

\author{
GF Piepel* \\ PA Krauter** \\ BG Amidan* \\ W Einfeld**
}

*Pacific Northwest National Laboratory, Richland, Washington

${ }^{* *}$ Sandia National Laboratories, Albuquerque, New Mexico

May 2011

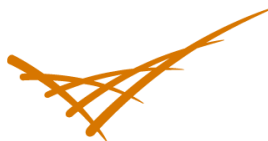

Pacific Northwest

NATIONAL LABORATORY

Proudly Operated by Battelle Since 1965 
Experimental Design for a SpongeWipe Study to Relate the Recovery Efficiency and False Negative Rate to the Concentration of a Bacillus anthracis Surrogate for Six Surface Materials

\author{
GF Piepel* \\ BG Amidan* \\ PA Krauter** \\ W Einfeld** \\ *Pacific Northwest National Laboratory, Richland, Washington \\ **Sandia National Laboratories, Albuquerque, New Mexico
}

May 2011

Prepared for

the U.S. Department of Energy

under Contract DE-AC05-76RL01830

Pacific Northwest National Laboratory

Richland, Washington 99352 


\section{Executive Summary}

This report describes the experimental design for a laboratory study planned under the auspices of the Validated Sampling Plan Working Group (VSPWG). The experimental design was jointly developed by Pacific Northwest National Laboratory (PNNL) and Sandia National Laboratories (SNL). The testing specified by the experimental design was performed by SNL.

The high-level drivers for this work were two concerns raised by the Government Accountability Office (GAO) following the 2001 contaminations of the Hart Senate office building and postal facilities via letters containing Bacillus anthracis (BA). These concerns involved 1) the lack of validated sample collection, processing, and analytical methods and 2) insufficient use of statistical sampling to provide for quantifying the confidence that part or all of a building can be cleared when all samples have negative results (GAO 2005a, 2005b). Critical to addressing both of these areas of concern is quantifying, for a single sample, the false-negative rate (FNR), or the probability of correct detection (PCD), where PCD = 1 - FNR. The FNR for a single sample may depend on the 1) method of contaminant deposition, 2) surface concentration of the contaminant, 3) surface material being sampled, 4) sample collection method, 5) sample storage and transportation method and conditions, 6) sample processing method, and 7) sample analytical (assay) method.

A review of the literature (Piepel et al. 2010) found 17 chamber and laboratory studies that 1) focused on swab, wipe, or vacuum samples collected from a variety of surface materials contaminated by BA or a surrogate and 2) used culture methods to determine the surface concentration of colony-forming units (CFUs). These studies generally quantified the performance of the sampling and analysis methods in terms of recovery efficiency (RE) and not FNR (or PCD). Only one study (Estill et al. 2009) developed equations for calculating PCD as a function of surface concentration. However, the data were insufficient in some regards, and the PCD equations were not published in the journal article. Hence, Piepel et al. ${ }^{\text {(a) }}$ noted that previous chamber and laboratory studies failed to quantify the FNR for a single sample as a function of affecting variables, and this left a major "gap" in available information. Quantifying the FNR for a single sample under a variety of conditions is a key aspect of 1) validating sample and analysis methods and 2) calculating the confidence in characterization or clearance decisions based on a statistical sampling plan. These are the two main areas of concern expressed by the GAO.

To partially address the gap in FNR results, the VSPWG planned a laboratory study to examine the performance of a sponge-wipe method with a BA surrogate at low concentrations. This report documents the experimental design developed for the sponge-wipe study and discusses the planned data analyses and results. The experimental work investigated the effects on key response variables of sponge-wipe samples taken from six surface materials contaminated with a range of surface concentrations of a BA surrogate, Bacillus atrophaeus. The key response variables include measures of the contamination on test coupons of surface materials (obtained from positive control samples), contamination recovered from coupons by sponge-wipe samples, RE, and FNR.

Ideally, swab and vacuum sample collection methods would also have been investigated in the laboratory study. However, available funding and several challenging aspects of the study led to the VSPWG decision to focus on a sponge-wipe sampling and analysis method recommended and validated by the Centers for Disease Control and Prevention (CDC). Similar studies can be performed in the future for swab and vacuum sampling methods. 
The original experimental design of the sponge-wipe study called for a chamber study with dry aerosol deposition of the contaminant on test coupons inside a test chamber. However, preliminary testing by SNL showed it was not possible to reliably achieve low enough concentrations on coupons to realize false negatives with the sponge-wipe method recommended by the CDC. Hence, concentrations achievable by dry aerosol deposition would not provide useful information to address the information gap on false negatives. Therefore, the plan was changed to perform a laboratory (bench-top) study using a liquid deposition method. This approach can reliably achieve lower concentrations of the contaminant on test coupons so that false negatives can be achieved. Data for overlapping concentrations (on the high end of wet deposition tests, and the low end of preliminary dry aerosol deposition tests) were collected as part of this study to provide a limited basis for assessing the impact on results of wet versus dry deposition of the contaminant.

The experimental design for the laboratory study investigated six nonporous surface materials in 16 test runs, performed in two blocks of eight runs each. Three surface materials (stainless steel, vinyl tile, and ceramic tile) were tested in Block 1, using eight concentrations of BA surrogate $(2,5,10,15,20,25$, 100 and 1200 spores per $645.16-\mathrm{cm}^{2}$ test coupon). The eight surface concentrations of the surrogate were randomly assigned to test runs within each block. It was expected that some of the very low concentrations would present challenges for deposition, sampling, and analysis. However, such tests were needed to investigate RE and FNR over the full range of concentrations of interest. The original plan was to replicate in Block 2 the set of eight runs from Block 1 using the same three surface materials (stainless steel, vinyl title, and ceramic tile). The purpose of that plan was to obtain increased accuracy and precision in results through replicate tests. However, the sponge-wipe method obtained fewer false negatives than expected in Block 1 for the first three surface materials, and the results for most of the concentrations had better precision than expected. So it was decided to test three more challenging surface materials in Block 2 (plastic, painted wood paneling, and faux leather). The eight surface concentrations tested in Block $2\left(5,10,15,20,25,35,50\right.$, and 100 spores per $645.16-\mathrm{cm}^{2}$ test coupon) were modified relative to the eight concentrations tested in Block 1 in an effort to increase the number of false negatives obtained during testing.

The experimental design for this laboratory study is a split-plot experiment (Steel and Torrie 1960, Chapter 12; Myers and Montgomery 1995, Section 9.6) in which "concentration" is the whole-plot (WP) factor and "surface material" is the sub-plot (SP) factor. In each of the 16 test runs (Block $1=$ Tests 1-8, Block 2 = Tests 9-16), there were 10 test coupons for each of the surface materials. This provided a good basis for calculating empirical FNR values (i.e., $F N R=x / 10$, where $x=$ number of false negatives). A positive control (reference) sample was generated at the same time as each test sample, which consisted of placing the same number of drops of contaminant solution on a growth plate as were placed on the test coupon. This provides a basis for estimating the actual contaminant concentration deposited on each test coupon (within the variation of the deposition process). For each of the six surface materials, the estimates of actual contaminant concentrations will be used during the data-analysis phase 1) to calculate RE values for the wipe sampling and analysis method and 2) as the concentrations for fitting RE- and FNR-concentration equations.

Data analyses for the sponge-wipe laboratory study will support 1) estimating the FNR for each combination of contaminant concentration and surface material, 2) estimating the surface concentrations (e.g., CFU/ $/ \mathrm{cm}^{2}$ ) and their uncertainties (e.g., standard deviation [SD] or percent relative standard deviation [\%RSD]) of the contaminant for each combination of concentration and surface material, 3 ) estimating RE (\%) and their uncertainties (SD or \% RSD) for each combination of contaminant 
concentration and surface material, 4) fitting FNR-concentration and RE-concentration equations for each of the six surface materials, 5) assessing goodness-of-fit of the equations, and 6) quantifying the uncertainty in FNR and RE predictions made with the fitted equations. Using the FNR-concentration equations that will be generated using the data from this study, it will be possible to calculate quantities such as the limit of detection for each surface material, as well as the predicted FNR for any concentration in the range tested.

In summary, the data resulting from the sponge-wipe laboratory study discussed in this report will support addressing both of the main concerns of the GAO, namely 1) contributing information toward validating the sponge-wipe method and 2) providing FNR values as a function of concentration and surface material for calculating the numbers of samples and confidence in characterization and clearance decisions based on statistical sampling plans when the FNR $>0$. 



\section{Acronyms}

\%RSD percent relative standard deviation

BA Bacillus anthracis

CDC Centers for Disease Control and Prevention

CFU colony forming unit

DHS U.S. Department of Homeland Security

DoD U. S. Department of Defense

DOE U.S. Department of Energy

EPA Environmental Protection Agency

FBI Federal Bureau of Investigation

FNR false negative rate

FPR false positive rate

GAO Government Accountability Office

LOD limit of detection

NIST National Institute of Standards and Technology

PCD probability of correct detection

PNNL Pacific Northwest National Laboratory

QC quality control

RE recovery efficiency

SD standard deviation

S\&T Science and Technology Directorate

SNL Sandia National Laboratories

SP sub-plot

U.S. United States

VSPWG Validated Sampling Plan Working Group

WP whole-plot 



\section{Acknowledgments}

The Pacific Northwest National Laboratory (PNNL) work summarized in this report was funded by the Standards Office of the Test and Evaluation/Standards Division and the Biological Research and Development Branch of the Chemical and Biological Division in the Science and Technology Directorate of the U.S. Department of Homeland Security (DHS). The interest and FY09 funding support of Bert Coursey (Standards Portfolio Executive) for the initial portion of work at PNNL is gratefully acknowledged. The interest and FY10-11 funding support of Lance Brooks and Chris Russell for the latter portion of the work is also gratefully acknowledged. PNNL is a multiprogram national laboratory operated for the U.S. Department of Energy by Battelle under Contract DE-AC05-76RL01830.

The Sandia National Laboratories (SNL) work included in this report was funded by the Chemical and Biological Research and Development Branch of the Chemical and Biological Division in the S\&T Directorate of DHS. The interest and support of Lance Brooks and Chris Russell (DHS) for the SNL work is gratefully acknowledged. SNL is a multiprogram national laboratory operated by Sandia Corporation, a Lockheed Martin company, for the U.S. Department of Energy's National Nuclear Security Administration under Contract DE-AC04-AL8500.

The work in this report was also influenced by telecon discussions and comments from Validated Sampling Plan Working Group (VSPWG) members during the planning and performance stages of this work. The authors would also like to thank Randy Long (DHS) for his leadership of the VSPWG and general guidance on this work. We also acknowledge and thank the following PNNL staff members: 1) Brett Matzke for reviewing and providing comments on a draft of this report and 2) Wayne Cosby for editing, formatting, and preparing the report for publication. 



\section{Contents}

Executive Summary …….................................................................................................. iii

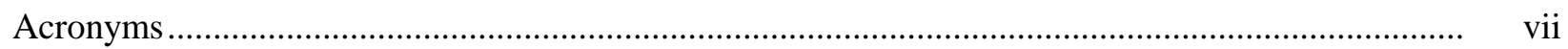

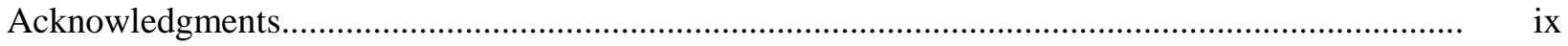

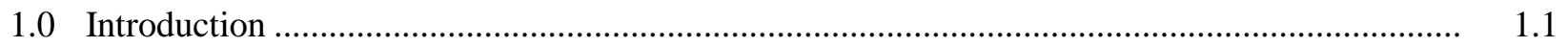

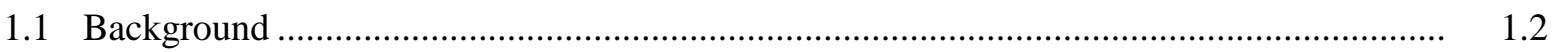

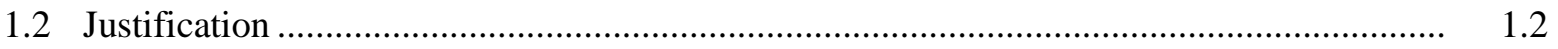

1.3 Performing Organizations and Funding .................................................................. 1.3

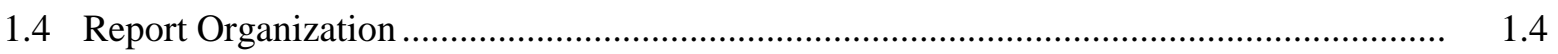

2.0 Factors Held Constant in the Sponge-Wipe Study …....................................................... 2.1

3.0 Factors Varied in the Sponge-Wipe Study ....................................................................... 3.1

4.0 Quality Control Samples in the Sponge-Wipe Study ............................................................

5.0 Preliminary Tests to Determine Contaminant Concentrations ................................................. 5.1

6.0 Experimental Design for the Sponge-Wipe Study ............................................................. 6.1

7.0 Gap Coverage, Advantages, and Disadvantages of this Study .............................................. 7.1

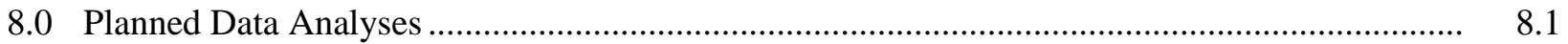

9.0 Recommendations for Future Studies ..................................................................... 9.1

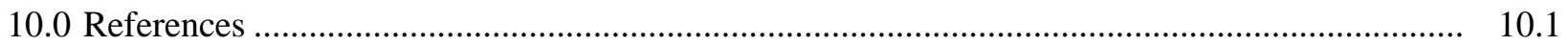

\section{Figures}

5.1. An Example of Eight Concentration Levels Selected to Span the Range of FNR Values for Three Surface Materials Tested Within a Block

6.1. Bench Testing Configuration Showing the Locations of the 30 Test Coupons $(1,2, \ldots, 30)$ and Six Negative Controls (NC1, .., NC6) for a Given Test Run...

\section{Tables}

2.1. Factors Held Constant in the VSPWG Sponge-Wipe Study ................................................ 2.1

3.1. Factors Varied in the VSPWG Sponge-Wipe Study.......................................................... 3.1

6.1. Test Matrix for Randomized Complete Block, Split-Plot Experimental Design of the VSPWG Sponge-Wipe Study .................................................................................... 6.2

6.2. Assignment of Surface Material Test Coupons to Bench Positions for Each Test Run ............. $\quad 6.4$

8.1. Information Summarized by Piepel et al. (2010) in Their Literature Review of Previous Chamber and Laboratory Studies for Sampling and Analyzing Contaminated Surfaces . 


\subsection{Introduction}

This report discusses the experimental design for a laboratory study planned under the auspices of the Validated Sampling Plan Working Group (VSPWG). The laboratory study is needed to address gaps identified by Piepel et al. (2010) in a review of 17 previous chamber and laboratory studies. The experimental design was developed by Pacific Northwest National Laboratory (PNNL) and Sandia National Laboratories (SNL), and the laboratory study was performed by SNL. Revision 0 this report was finished after the first block of testing was completed, and the second block had begun. Revision 1 of this report documents the testing performed after both blocks of testing were completed, because some additional changes were made in the experimental design during Block 2.

The laboratory study collected data to characterize the performance of sponge-wipe sample collection, extraction, and analysis procedures developed by the Centers for Disease Control and Prevention (CDC). The sponge-wipe sampling method is also recommended in the VSPWG sampling strategy document. ${ }^{\text {(a) }}$ The sponge-wipe study investigated the effects of selected independent variables on several response (dependent) variables. For several reasons, it was necessary to limit the number of independent variables investigated in the sponge-wipe study. The two independent variables that were varied in the study are the surface concentration of a Bacillus anthracis (BA) surrogate (Bacillus atrophaeus) and surface material. Six non-porous surface materials (stainless steel, vinyl tiles, ceramic tile, plastic, painted wood paneling, and faux leather) having a range of surface roughness values were investigated. Three materials (stainless steel, vinyl tiles, and ceramic tile) were investigated in the first block of eight test runs, while the remaining three materials were investigated in a second block of eight test runs. Eight surface concentrations of surrogate spores (including some very low concentrations) were investigated, with a slightly different set of concentrations for the two blocks of tests. The variables that were held constant and varied in the sponge-wipe study are discussed further in Sections 2 and 3, respectively. The response variables for which data were collected include measures of the 1) contamination on positive control samples paired with test coupons, 2) contamination recovered from test coupons by wipe samples, 3) recovery efficiency (RE), and 4) false negative rate (FNR).

The tests in the sponge-wipe study were conducted according to the experimental design presented in Section 6. To limit sources of bias that might impact the experimental data, the experimental design randomized some aspects of testing and data collection.

Concentrations of BA necessary to cause illness or symptoms may include values low enough that the FNR $>0$. Hence, estimates of FNR, RE, and other quantities (e.g., limits of detection) for single samples taken under various sampling conditions are needed as inputs to calculate the confidence in detection or clearance decisions based on sampling and analysis results after a contamination event. The sponge-wipe study generated data to support developing RE and FNR equations as functions of contaminant surface concentration for each of the six surface materials. These RE-concentration and FNR-concentration equations will then be available to provide inputs for calculating 1) the numbers of samples in statistically based sampling plans to provide the desired confidence for detection and clearance decisions and 2) the confidence in detection and clearance decisions given the numbers of samples in specific sampling plans.

(a) Environmental Sampling Strategy for Bacillus anthracis during Crisis and Consequence Management (Draft Version 4-pre-decisional), Validated Sampling Plan Working Group, October, 2010. 
Sections 1.1 and 1.2 present, respectively, the background and justification for the work in this report. Section 1.3 discusses the organizations that performed work and their funding sources. Section 1.4 outlines the organization of the rest of the report.

\subsection{Background}

In 2001, letters containing BA contaminated the Hart Senate office building in Washington, DC and postal facilities that processed the letters. This experience identified areas of concern in the procedures and methods used to characterize and clear buildings contaminated by BA. A congressional inquiry and the Government Accountability Office (GAO) identified two main concerns (GAO 2005a, 2005b). One main concern was the reliance on sampling specific areas where it was thought BA would be found. This type of sampling approach is referred to as targeted sampling or judgmental sampling. The GAO reports identified the need to use statistical (probabilistic) sampling so that when all results are negative, a building (or area within a building) can be cleared with a known level of statistical confidence. The second main concern was that the sample collection, processing, and analytical methods used were not validated. The lack of validated methods raised questions about the reliability of the negative sampling results.

The VSPWG was formed in July 2006 in response to the congressional inquiry and GAO reports. The VSPWG is headed by the U.S. Department of Homeland Security (DHS) Science and Technology Directorate (S\&T) and includes experts from CDC, the Environmental Protection Agency (EPA), the National Institute of Standards and Technology (NIST), the Federal Bureau of Investigation (FBI), the Department of Defense (DoD), and U.S. national laboratories (PNNL and SNL currently). The VSPWG is developing a sampling strategy for biological contamination ${ }^{(a)}$ and is working towards validating methods for steps in the sampling process. These steps include 1) sampling approach (e.g., appropriate uses of judgmental and probabilistic sampling), 2) sample collection methods, 3) handling of samples (e.g., handling, storage, and transportation), 4) sample processing and extraction methods (i.e., extraction of the contaminant from samples), and 5) sample analysis (i.e., analytical methods).

\subsection{Justification}

The results of the sponge-wipe study conducted using the experimental design in this report will contribute to addressing both of the GAO's main concerns. Specifically, for sponge-wipe samples collected, extracted, and analyzed using the specified methods, the study will yield equations relating the FNR to the surface concentration of a BA surrogate for each of the six surface materials. The six surface materials tested in the sponge-wipe study span the range of surface roughness for non-porous surfaces. This may provide the basis for assessing the FNR as a function of the BA surrogate concentration for additional non-porous surface materials as a function of surface material characteristics.

The FNR equations will be developed from data generated by the study conducted according to the experimental design documented in this report. These equations (and the underlying data) will make a significant contribution to the validation of sponge-wipe sample collection, extraction, and analysis by quantifying the performance of the $\mathrm{CDC}$-validated methods over a range of $\mathrm{BA}$ surrogate concentrations

(a) Environmental Sampling Strategy for Bacillus anthracis during Crisis and Consequence Management (Draft Version 4-pre-decisional), Validated Sampling Plan Working Group, October, 2010. 
and surface types. Hence, this work addresses one of the two main concerns of the GAO, namely method validation.

The FNR equations will also serve as inputs to formulas for calculating the 1) numbers of samples required to make characterization and clearance decisions with specified levels of confidence and 2) confidence in characterization and clearance decisions for specific sampling plans implemented in BA contamination events. The work to develop these formulas is part of another task in the PNNL project supporting the VSPWG and will be documented in a separate, future report. However, the experimental design for the sponge-wipe study discussed in this report will generate key data on the FNR for a single sponge-wipe sample. Clearly, the FNR for a single sponge-wipe sample will depend on the concentration of the contaminant and the surface material being wiped. The FNR for a single sample is a key input to calculations for the confidence in characterization and clearance decisions based on statistical sampling. Hence, this work contributes to addressing the other main GAO concern-having confidence in decisions based on statistical sampling.

The need for the sponge-wipe study discussed in this report was partly motivated by a review of the literature on previous chamber and laboratory studies by PNNL and NIST (Piepel et al. 2010). The literature review focused mainly on studies that collected swab, wipe, or vacuum samples from surfaces contaminated by BA or a surrogate and used culture methods to determine the surface concentration of the contaminant. A total of 17 studies were identified, with 14 studies having swab data, 9 studies having wipe data, and 4 studies having vacuum data. Only one of the studies used their data to develop equations relating probability of correct detection (PCD) to the concentration of the contaminant, although that aspect of the study was not included in the published journal article (Estill et al. 2009). Only one other study tested a sufficient number of contaminant concentrations to potentially develop PCD/FNRconcentration equations. Hence, Piepel et al. (2010) noted that quantifying the FNR (or PCD) in a single sample as a function of contaminant concentration and surface material was a major gap in the previous chamber and laboratory studies. The study and experimental design presented in this report fills this major gap for the CDC-validated sponge-wipe collection, extraction, and analysis methods.

\subsection{Performing Organizations and Funding}

The work in this report was performed by staff in the Applied Statistics and Computational Modeling group at PNNL and by staff in the Chemical and Biological Systems group at SNL. The specific contributors are listed as authors of this report. Discussions with, and inputs by, members of the VSPWG (see Section 1.1) also guided the work.

The PNNL work was funded by two divisions within DHS S\&T: 1) the Standards Office of the Test and Evaluation/Standards Division and 2) the Chemical and Biological Research and Development Branch of the Chemical and Biological Division. The work was funded under the prime contract DE-AC05-76RL01830 between the U.S. Department of Energy (DOE) and the operator of PNNL for research, testing, evaluation, and/or development activities and pursuant to Section 309(a)(1)(c) of the Homeland Security Act of 2002 (Public Law 107-296), which authorizes DHS to task the DOE national laboratories on a "work for others" basis.

The SNL work was funded by the Chemical and Biological Research and Development Branch of the Chemical and Biological Division in DHS S\&T. SNL is a multiprogram national laboratory operated by 
Sandia Corporation, a Lockheed Martin company, for DOE's National Nuclear Security Administration under Contract DE-AC04-AL8500.

\subsection{Report Organization}

The remainder of this report describes the experimental design for the VSPWG sponge-wipe study and the basis for its development. The report is organized as follows. The factors that were held constant in the experimental design are discussed in Section 2. The factors that were varied in the experimental design are discussed in Section 3. The quality control (i.e., positive and negative controls) samples that were included in the sponge-wipe study are discussed in Section 4. Preliminary tests that were used to determine the surface concentration levels of the surrogate contaminant are discussed in Section 5. The experimental design for the VSPWG sponge-wipe study is presented and discussed in Section 6. All of the gaps identified in previous chamber and laboratory studies could not be filled in this sponge-wipe study, so the advantages and disadvantages of the study are given in Section 7. The data analyses that will be supported by the chosen experimental design are described in Section 8. Recommendations for future studies are presented in Section 9. The references cited in the report are listed in Section 10. 


\subsection{Factors Held Constant in the Sponge-Wipe Study}

Table 2.1 lists the factors that were held constant during the sponge-wipe study. The sponge-wipe sampling method was selected for this study over the swab sampling method because swabs 1) had the most information available in previously conducted chamber and laboratory studies (Piepel et al. 2010) and 2) are the least frequently used sample collection method. There were several reasons for selecting wipe sampling over vacuum sampling methods. Although vacuum sampling methods have the least information available in the literature, they were considered to be too inconsistent and difficult to work with given the goals and objectives of this study. Also, while the vacuum method offers much appeal for reducing the limits of detection for surface sampling, currently used methods involve the use of a "leaky" dust collection sock with demonstrated low overall spore RE. Finally, the vacuum method is further complicated by the need for considerable media manipulation and handling in the laboratory. For all of these reasons, this study focuses on sponge-wipe samples, collected per methods developed by the CDC.

Table 2.1. Factors Held Constant in the VSPWG Sponge-Wipe Study

\begin{tabular}{|c|c|}
\hline Factor & Test Level \\
\hline Sample collection media & Wipe $^{(a)}$ \\
\hline Sample/Coupon Size & 10-inch by 10 -inch \\
\hline Wetting agent & Per method ${ }^{(a)}$ \\
\hline BA surrogate & Bacillus atrophaeus \\
\hline Interfering material & None (clean surfaces) \\
\hline Deposition & Wet deposition \\
\hline Storage/transportation & None \\
\hline Laboratories & One $(\mathrm{SNL})^{(\mathrm{b})}$ \\
\hline Preparation/extraction & Per method $^{(a)}$ \\
\hline Analytical method & Culture \\
\hline \multicolumn{2}{|c|}{$\begin{array}{l}\text { (a) The wipe sample collection and analysis methods are based on methods } \\
\text { developed by CDC and will be documented separately by SNL. } \\
\text { (b) Lab-to-lab variation is typically a major contributor to reproducibility } \\
\text { uncertainty, which ideally would be estimated via tests at several } \\
\text { laboratories. However, the available funding is not sufficient to use } \\
\text { different laboratories as part of the study. }\end{array}$} \\
\hline
\end{tabular}

The plan, prior to the start of testing, was to perform a chamber study with dry, aerosol deposition of the contaminant on test coupons inside a test chamber. However, preliminary testing by SNL showed it was not possible to reliably achieve low enough concentrations on coupons to realize false negatives with the CDC-validated, sponge-wipe method (which has improved efficiency compared to other wipe methods). Hence, the plan was changed to perform a laboratory (bench-top) study using a liquid deposition method (which can reliably achieve lower concentrations of the contaminant on test coupons), so that adequate numbers false negatives could be obtained. 
Preparation/extraction methods, storage/transportation factors, and analytical laboratories were held constant in this sponge-wipe study. The summary of previous chamber and laboratory studies (Piepel et al. 2010) identified 1) preparation/extraction factors to be very important to sampling efficiency and 2) a near absence in the literature of information about storage/transportation and laboratory effects. However, varying these factors in addition to the factors selected for varying in this test (discussed in Section 2) would comprise a very large study and be beyond the scope of this effort. Hence, it is envisioned that these factors could be investigated in future chamber or laboratory studies. 


\subsection{Factors Varied in the Sponge-Wipe Study}

Table 3.1 lists the factors that were varied in the sponge-wipe study. Six surface materials were tested: stainless steel, vinyl tiles, ceramic tiles, plastic, painted wood paneling, and faux leather. These materials were selected to span the range of surface roughness of non-porous materials (Shellenberger and Logan 2002, Hallas and Shaw 2006).

Eight different surface concentration levels were chosen to span the range of FNR values ( 0 to 1$)$ for each of two sets of three surface materials. How the eight concentration levels were chosen for the two blocks of tests is discussed in Section 5. The number of concentrations (eight) was chosen to protect against the possibility that the 1) lowest two concentrations yield FNR 1 and 2) highest two concentrations yield FNR $\sim 0$. In such a case, there would still be four concentrations to span the interior of the 0 to 1 range for FNR.

Table 3.1. Factors Varied in the VSPWG Sponge-Wipe Study

\begin{tabular}{|c|c|}
\hline Factor & Test Levels \\
\hline Surface materials & $\begin{array}{l}\text { Stainless steel, vinyl tile, ceramic tile, plastic, painted wood } \\
\text { paneling, and faux leather. }\end{array}$ \\
\hline $\begin{array}{l}\text { Contaminant surface } \\
\text { concentrations }\end{array}$ & $\begin{array}{l}\text { Eight different concentrations (determined from preliminary } \\
\text { tests-see Section 5). }{ }^{\text {(a) }}\end{array}$ \\
\hline Number of test runs & $\begin{array}{l}\text { 16-Eight runs at eight nominal contaminant concentrations } \\
\text { were performed in each of two blocks (sets), resulting in } 16 \\
\text { runs total. Block } 1 \text { tested stainless steel, vinyl tile, and } \\
\text { ceramic tile, while Block } 2 \text { tested plastic, painted wood } \\
\text { paneling, and faux leather. }{ }^{\text {(a) }}\end{array}$ \\
\hline $\begin{array}{l}\text { Number of test coupons in a } \\
\text { test run }\end{array}$ & $\begin{array}{l}30 \text { - There were } 10 \text { test coupons of each surface material } \\
\text { within a run. Positive and negative controls increased the } \\
\text { total number of samples in a run. }\end{array}$ \\
\hline $\begin{array}{l}\text { Personnel for sample } \\
\text { collection, processing, and } \\
\text { analysis }\end{array}$ & $\begin{array}{l}\text { Three personnel per test run were available to perform the } \\
\text { sample collection, extraction, and analytical steps of the } \\
\text { work. }\end{array}$ \\
\hline
\end{tabular}

It was originally planned to test a set of eight concentrations on the first three surface materials (stainless steel, vinyl tile, and ceramic tile) twice (in two blocks), which would have provided for 1) quantifying the uncertainty in test results for the three surface materials, 2) increasing the accuracy and precision of results, and 3) assessing the goodness-of-fit of the equations that will be developed from the data to relate response variables (e.g., RE and FNR) to contaminant concentrations for the three surface materials. However, results from the Block 1 tests had better precision than expected, and occurrences of false negatives at the lowest concentrations were fewer than expected. Thus, it was decided that a better use of the Block 2 tests would be to study the performance of the sponge-wipe method for three additional non-porous surface materials, with at least one or two of those materials providing a more difficult challenge for the sponge-wipe method. 
There were 30 test coupons within each test run (not counting positive and negative controls, which are discussed in Section 4). These 30 test coupons consisted of 10 test coupons from each of the three surface materials tested in Block 1 or Block 2. Having 10 coupons for each surface material will provide a good basis for fitting FNR-concentration equations. Each test coupon had an associated positive control (reference) sample, which will be used to estimate the actual contaminant concentration on each test coupon (within deposition uncertainties). The reference samples consisted of putting the same number of drops of contaminant solution on a growth media plate as were put on a test coupon. A reference sample was done immediately before each test coupon so that there is a one-to-one correspondence. The contaminant concentrations from the reference samples will be used to fit FNR-concentration equations and to calculate RE values (which will be used in fitting RE-concentration equations). See Section 8 for further discussion of data analyses that can be performed using data from the experimental design presented in this report.

Three technicians performed the sample collection, extraction, and analysis (i.e., plating and counting) steps of the sampling and analysis work. The personnel performing each task in the process was varied as part of the experimental design, as discussed in Section 6. 


\subsection{Quality Control Samples in the Sponge-Wipe Study}

Each test run in the sponge-wipe study included a complement of quality-control (QC) samples, which were thoroughly documented in the SNL test procedures. We provide a brief overview here because the numbers and placements of positive control (reference) samples are an important part of the experimental design for the study.

The positive controls consisted of one reference sample per test coupon, with the reference sample produced immediately before the corresponding spore-seeded test coupon. The reference samples involved putting the same number of drops of contaminant solution directly on a growth media plate as were put on the corresponding test coupon. The negative controls consisted of 1) blank coupons that were processed the same as spore-seeded coupons and 2) blank wipes that were taken out of their package, placed in the appropriate specimen container, and processed the same as wipe samples of contaminated coupons. Additional details regarding the positive and negative controls are provided in the SNL procedures for the experimental work.

The positive controls provide for quantifying the REs and FNRs associated with the sponge-wipe sampling and analysis method for each combination of eight concentrations and six surface materials. The negative controls are process controls; hence, a positive result on any negative control sample would invalidate the corresponding test. However, positive results on negative control samples will be documented because they provide for estimating the false positive rate (FPR) of the method. 


\subsection{Preliminary Tests to Determine Contaminant Concentrations}

Preliminary "range finding" tests were performed before Tests 1-8 (Block 1) and Tests 9-16 (Block 2 ) in the sponge-wipe study to determine the eight surface concentration levels that were used for testing in Block 1 and Block 2, respectively. Because different surface materials were tested in Blocks 1 and 2, and the concentrations for Block 2 were selected based on the results for Block 1, the eight concentrations were not be the same for the two blocks. Each of the two sets of eight concentrations of the BA surrogate (Bacillus atrophaeus) were selected with the goal that 1 ) the lowest concentration is rarely detected $(\mathrm{PCD} \approx 0 / \mathrm{FNR} \approx 1), 2$ ) the highest concentration is nearly always detected ( $\mathrm{PCD} \approx 1 / \mathrm{FNR} \approx 0$ ), and 3 ) intermediate concentrations have PCD/FNR values spanning the range of 0 to 1 . The data from Tests 1-8 (Block 1) and Tests 9-16 (Block 2) will be used to fit an FNR-concentration curve and REconcentration curve for each of the six surface materials. The eight concentration levels for each block were selected considering all three surface materials to be tested in that block. Figure 5.1 shows an example of the goal for choosing the concentration levels, taking into account the three surface materials in Block 1 (stainless steel, vinyl tile, ceramic tile) and Block 2 (plastic, painted wood paneling, and faux leather). The three colored curves in Figure 5.1 represent a hypothetical relationship between FNR and concentration for each of three surface materials.

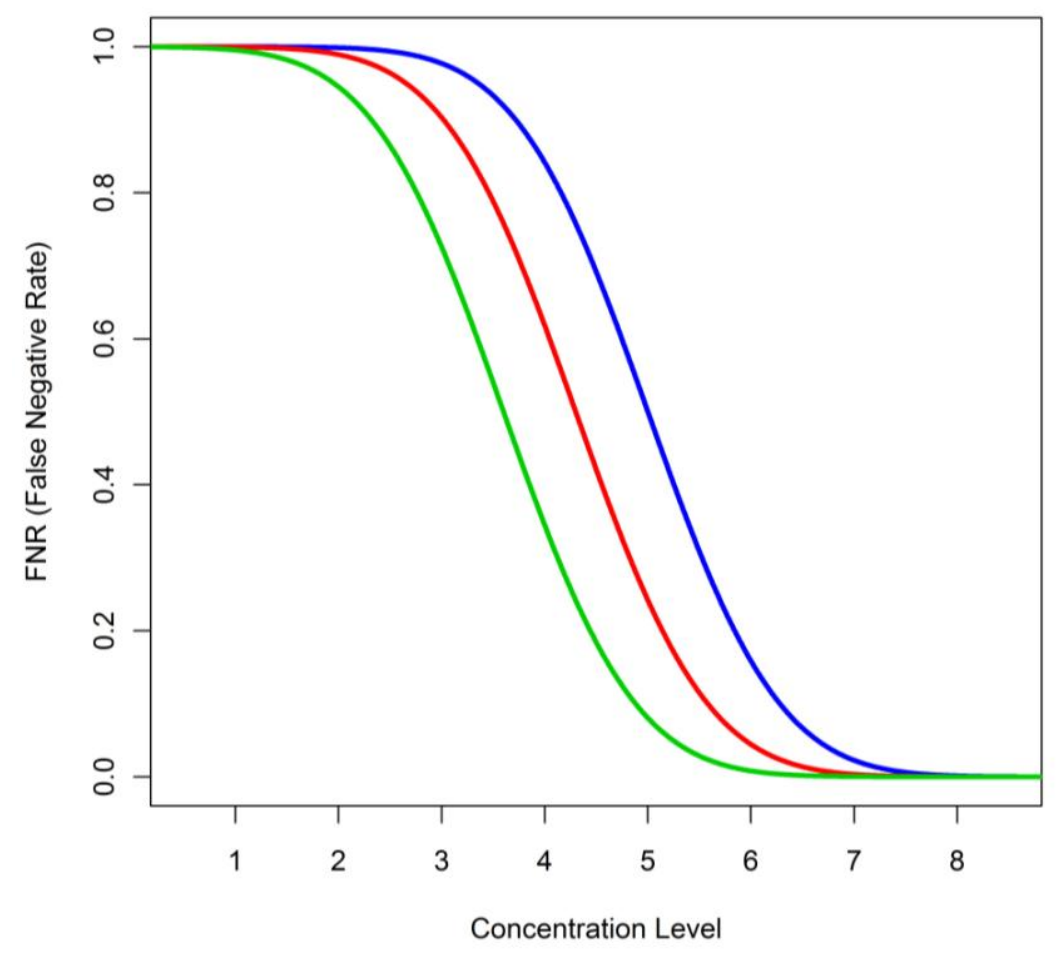

Figure 5.1. An Example of Eight Concentration Levels Selected to Span the Range of FNR Values for Three Surface Materials Tested Within a Block. The three curves represent hypothetical relationships between FNR and concentration. 
The set of eight concentrations for each block of tests was chosen with the expectation that no more than two of the concentrations (for any of the set of three surface materials) would yield FNR values equal or very close to 0 or to 1 . For example, suppose for a given surface material that the two smallest concentrations (\#1 and \#2 in Figure 5.1) yield FNR = 1, while the two largest concentrations (\#7 and \#8 in Figure 5.1) yield FNR $=0$. That would leave four concentrations to yield FNR values with intermediate values of $0<$ FNR $<1$. Three to four concentrations with intermediate FNR values would be the minimally acceptable basis (during the data analysis phase of work described in Section 8) to fit sigmoidal equations to the FNR-concentration data. Ideally for each surface material, six of the eight concentrations would yield intermediate values of FNR, with only the smallest concentration yielding $\mathrm{FNR}=1$, and only the largest concentration yielding FNR $=0$.

As discussed in Section 2, the original plan to perform a chamber study with dry aerosol deposition of the contaminant on test coupons inside a test chamber was changed when preliminary aerosol test results demonstrated that concentrations low enough to characterize the FNR could not be accomplished using the aerosol method. The plan was changed to perform a laboratory (bench-top) study using a liquid deposition method, which reliably achieved lower concentrations of the contaminant on test coupons so that a range of FNRs could be achieved. Because of this change in plans, a secondary objective was added to the laboratory study to allow for comparing dry aerosolization and liquid deposition methods. The secondary objective called for selecting concentrations for liquid deposition that overlapped with the concentrations for dry aerosol deposition investigated by SNL in preliminary tests. It would be desirable to have at least two concentrations in the liquid-deposition study that were also tested in preliminary dry aerosol deposition tests. This would provide a basis for quantifying any difference in results for liquid deposition versus dry aerosol deposition. However, it is already known that the lowest contaminant concentrations that could be achieved by dry aerosol deposition yielded FNR $=1$. Hence, it may not be possible to achieve the secondary goal without partially violating the primary goal (i.e., having no more than two liquid-deposition concentrations with $\mathrm{PCD}=1$ ), or vice versa.

In summary, the specific concentrations tested in the study were chosen by SNL and PNNL based on preliminary liquid-deposition tests before each of the Block 1 and Block 2 tests. Also, the results from the Block 1 tests were considered in selecting the concentrations for the Block 2 tests. Further, results from tests of the first few concentrations tested in Block 2 were used to select one of the remaining concentrations to be tested in Block 2 (while still maintaining a randomized testing order of concentrations). 


\subsection{Experimental Design for the Sponge-Wipe Study}

The experimental design for the 16 test runs is a split-plot experiment (Steel and Torrie 1960, Chapter 12; Myers and Montgomery 1995, Section 9.6) run in two blocks. Originally, it was planned to test the same three surface materials in Block 1 and Block 2 with the same eight surface concentrations (although in a different randomized order in each block). However, when Block 1 results showed 1) lower-thanexpected FNRs for the lowest concentrations and 2) higher-than-expected precision in the sampling method for the original three surface materials, it was decided to test three different surface materials in Block 2. Hence, Block 1 contains Tests 1-8 with one set of eight concentrations, using stainless steel, vinyl tile, and ceramic tile as the three surface materials. In addition, Block 1 contains a replicate run of Test 4 performed after Test 8 . Block 2 contains Tests $9-16$ of a slightly different set of eight concentrations, using plastic, painted wood paneling, and faux leather. In addition, Block 2 contains a replicate run of Test 11 performed after Test 16. The replication of a test run within each block provides a limited basis for estimating WP uncertainty. The block, split-plot, and randomization aspects of the experimental design are further described in the following paragraphs.

The eight concentrations tested in each block were run in a randomly assigned order to protect against confounding any possible time-trend effects with concentration effects over the eight runs within each block. A split-plot experiment results because one concentration must be applied to all coupons/tests in a given test run. In the terminology of split-plot experiments, the test runs are the whole-plot (WP) units, and concentration is the WP treatment factor (with eight concentration levels of the factor). Within a test run, the three non-porous surface materials were investigated with 10 test coupons for each material. Hence, the sub-plot (SP) units are the coupons, and the SP treatment factor is the surface material type. ${ }^{(a)}$ The assignment of surface materials to the 30 test coupons ( 3 materials $\times 10$ coupons each) is discussed subsequently. The basic concept and terminology of split-plot experiments is introduced because it may have to be accounted for in analyzing the resulting data, depending on how the data are analyzed.

Table 6.1 lists the general aspects of the split-plot experimental design for the VSPWG sponge-wipe study. The test numbers listed in the first column of Table 6.1 represent the run-order of the test runs as well as the test numbers. The eight concentration levels tested in a given block were randomly assigned to the test runs within that block, as shown in Table 6.1. The last four columns of Table 6.1 show assignments of four tasks to the three technicians who performed the tests. These tasks consisted of (a) sample collection on Benches 1 and 3, (b) sample collection on Benches 2 and 4, (c) sample processing, and (d) sample enumeration. The sample positions on the four test benches are represented in Figure 6.1. Technicians were assigned to tasks (a) to (d) in a nearly balanced way, although in Block 1 the technician performing task (c) was the same as one of those who performed task (a) or (b). The nearly balanced assignment of technicians to the testing jobs protects against technician effects (if any) possibly becoming confounded with the effects of concentration and surface material (the main test factors).

(a) The split-plot, whole-plot, and sub-plot terminologies come from the original application of split-plot designs in agricultural field trials. The terminology has been retained in the literature, even though split-plot experiments are widely used in many application areas. 
Table 6.1. Test Matrix for Randomized Complete Block, Split-Plot Experimental Design of the VSPWG Sponge-Wipe Study ${ }^{(a)}$

\begin{tabular}{|c|c|c|c|c|c|c|c|c|c|c|c|}
\hline $\begin{array}{l}\text { Test } \\
\text { Run } \\
\end{array}$ & Block & $\begin{array}{c}\text { Concen- } \\
\text { tration }^{(b)} \\
\text { (Spores/ } \\
\text { Coupon) }\end{array}$ & $\begin{array}{c}\text { \# Test } \\
\text { Coupons }\end{array}$ & $\begin{array}{c}\text { \# Test } \\
\text { Coupons }\end{array}$ & $\begin{array}{c}\text { \# Test } \\
\text { Coupons }\end{array}$ & $\begin{array}{l}\text { \# Positive } \\
\text { Controls }^{(c)}\end{array}$ & $\begin{array}{l}\text { \# Negative } \\
\text { Controls }^{(d)}\end{array}$ & 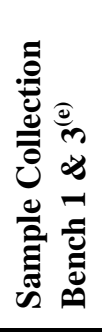 & 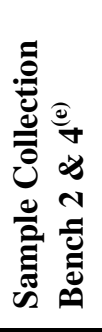 & 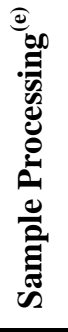 & \\
\hline & & & $\begin{array}{c}\text { Stainless } \\
\text { Steel }\end{array}$ & $\begin{array}{l}\text { Vinyl } \\
\text { Title }\end{array}$ & $\begin{array}{c}\text { Ceramic } \\
\text { Tile }\end{array}$ & & & & & & \\
\hline 1 & 1 & 20 & 10 & 10 & 10 & 30 & 8 & 1 & 2 & 2 & 3 \\
\hline 2 & 1 & 25 & 10 & 10 & 10 & 30 & 8 & 2 & 3 & 3 & 1 \\
\hline 3 & 1 & 2 & 10 & 10 & 10 & 30 & 8 & 3 & 1 & 1 & 2 \\
\hline $4 a$ & 1 & 10 & 10 & 10 & 10 & 30 & 8 & 1 & 2 & 1 & 3 \\
\hline 5 & 1 & 5 & 10 & 10 & 10 & 30 & 8 & 3 & 1 & 3 & 2 \\
\hline 6 & 1 & 100 & 10 & 10 & 10 & 30 & 8 & 2 & 3 & 2 & 1 \\
\hline 7 & 1 & 15 & 10 & 10 & 10 & 30 & 8 & 1 & 3 & 1 & 2 \\
\hline 8 & 1 & 1200 & 10 & 10 & 10 & 30 & 8 & 2 & 1 & 2 & 1 \\
\hline \multirow[t]{2}{*}{$4 \mathrm{~b}$} & 1 & 10 & 10 & 10 & 10 & 30 & 8 & 3 & 2 & 1 & 3 \\
\hline & & & $\begin{array}{c}\text { Faux } \\
\text { Leather }\end{array}$ & Plastic & $\begin{array}{c}\text { Painted } \\
\text { Wood }\end{array}$ & & & & & & \\
\hline 9 & 2 & 5 & 10 & 10 & 10 & 30 & 8 & 2 & 3 & 3 & 2 \\
\hline 10 & 2 & 35 & 10 & 10 & 10 & 30 & 8 & 1 & 2 & 3 & 1 \\
\hline $11 \mathrm{a}$ & 2 & 15 & 10 & 10 & 10 & 30 & 8 & 3 & 1 & 2 & 3 \\
\hline 12 & 2 & 50 & 10 & 10 & 10 & 30 & 8 & 2 & 3 & 1 & 1 \\
\hline 13 & 2 & 20 & 10 & 10 & 10 & 30 & 8 & 3 & 1 & 2 & 2 \\
\hline 14 & 2 & 100 & 10 & 10 & 10 & 30 & 8 & 1 & 2 & 3 & 2 \\
\hline 15 & 2 & 10 & 10 & 10 & 10 & 30 & 8 & 2 & 1 & 1 & 3 \\
\hline 16 & 2 & 25 & 10 & 10 & 10 & 30 & 8 & 3 & 2 & 1 & 2 \\
\hline $11 \mathrm{~b}$ & 2 & 15 & 10 & 10 & 10 & 30 & 8 & 1 & 3 & 2 & 3 \\
\hline
\end{tabular}

(a) Specifics of the test matrix for each test run not shown in this table are given in Table 6.2.

(b) The concentrations are the numbers of spores/coupon, where the coupons are $10 \mathrm{in} . \times 10 \mathrm{in} .\left(645.16 \mathrm{~cm}^{2}\right)$. The concentrations were tested in a random order within each block.

(c) There was one positive control (reference) sample for each of the 30 test coupons (10 coupons each of the three surface materials) in a test run. This is a critical aspect of the experimental design because it enables adjusting the wipe sample results for any effects of coupon location, time trend, or other "nuisance variables."

(d) There were two kinds of negative controls, with a total of eight per test run. For each test run, there were 1) two blank (uncontaminated) coupons of each of the three surface materials and 2) two blank wipes (removed from their packages and immediately placed in the same kind of sample containers used for contaminated sample coupons).

(e) Three technicians performed the four testing tasks for a given test run. These tasks were (a) sample collection Benches 1 and 3, (b) sample collection Benches 2 and 4, (c) sample processing, and (d) sample enumeration. The numbers 1, 2, and 3 represent the specific technician assigned to perform each task for each test run. For logistics reasons, the technician who performed task (c) is one of the technicians who performed tasks (a) or (b). 


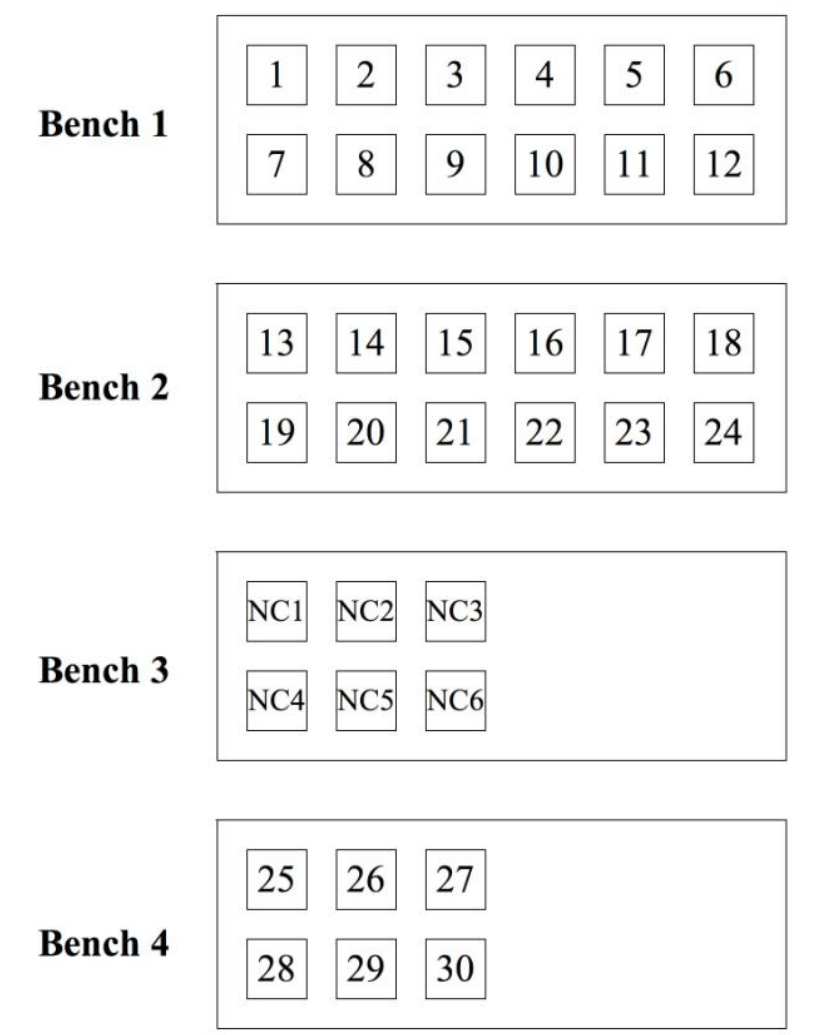

Figure 6.1. Bench Testing Configuration Showing the Locations of the 30 Test Coupons $(1,2, \ldots, 30)$ and Six Negative Controls (NC1, .., NC6) for a Given Test Run. Note that the bench-tops and coupon locations are not drawn to scale and are a pictorial representation only.

The contaminant deposition and sample collection aspects of the testing were performed on benches (each 72 inches long and 36 inches wide) located in the center of a room. Up to 18 of the 10 -in. $\times 10$-in. test coupons would have fit on each bench. Originally only 24 (instead of 30) coupons were to be tested in each test run, so it was decided to put 12 coupons per bench on two benches. However, subsequently the decision was made to have 30 coupons (10 each of the three surface materials) per test run. This necessitated two benches each with 12 sample coupon locations (Benches 1 and 2), and another bench with 6 sample coupon locations (Bench 4).

Table 6.2 lists (for each of the 16 test runs) the assignments of the 10 coupons for each set of three surface materials to the 30 bench positions (shown in Figure 6.1). The assignment of surface materials to bench positions 1 to 24 was performed using an optimal experimental design approach (Atkinson et al. 2007) implemented using SAS (2008) so that the split-plot structure of the experiment, as well as the effects of the block variable, concentrations (runs) within blocks, and bench positions could be accounted for during data modeling and analysis. The decision to test 10 coupons of each surface material rather than 8 came after the assignment of materials to 24 bench positions was made for Block 1 and Block 2 tests. There was not sufficient time to re-run the optimal experimental design approach to assign the surface materials to 30 bench positions before Block 1 tests, so the assignments for positions 25 to 30 in both Blocks 1 and 2 were made separately (see Table 6.2). 
Table 6.2. Assignment of Surface Material Test Coupons ${ }^{(a)}$ to Bench Positions for Each Test Run

\begin{tabular}{|c|c|c|c|c|c|c|c|c|c|c|c|c|c|c|c|c|c|c|}
\hline \multirow{5}{*}{$\begin{array}{l}\text { Bench }^{(\mathbf{b})} \\
\text { Position }\end{array}$} & \multicolumn{18}{|c|}{ Test Run } \\
\hline & 1 & 2 & 3 & $4 \mathbf{4 a}$ & 5 & 6 & 7 & 8 & $\mathbf{4 b}$ & 9 & $\mathbf{1 0}$ & 11a & 12 & 13 & 14 & 15 & 16 & 11b \\
\hline & \multicolumn{9}{|c|}{ Block 1} & \multicolumn{9}{|c|}{ Block 2} \\
\hline & \multicolumn{9}{|c|}{ Concentration (spores/coupon) $^{(\mathrm{c})}$} & \multicolumn{9}{|c|}{ Concentration (spores/coupon) ${ }^{(\mathrm{c})}$} \\
\hline & 20 & 25 & 2 & 10 & 5 & 100 & 15 & 1200 & $\mathbf{1 0}$ & 5 & 35 & 15 & 50 & 20 & 100 & 10 & 25 & 15 \\
\hline 1 & $\mathrm{~V}$ & $\mathrm{~S}$ & $\mathrm{C}$ & $\mathrm{V}$ & $\mathrm{C}$ & $\mathrm{V}$ & $\mathrm{S}$ & $\mathrm{C}$ & $\mathrm{C}$ & $\mathrm{P}$ & $\mathrm{L}$ & $\mathrm{W}$ & $\bar{P}$ & $\mathrm{~W}$ & $\mathrm{P}$ & $\mathrm{L}$ & $\mathrm{W}$ & $\mathrm{W}$ \\
\hline 2 & $\mathrm{~S}$ & $\mathrm{C}$ & $\mathrm{C}$ & $\mathrm{V}$ & $\mathrm{C}$ & V & $\mathrm{S}$ & V & $\mathrm{C}$ & $\mathrm{L}$ & W & W & $\mathrm{P}$ & W & $\mathrm{P}$ & $\mathrm{L}$ & $\mathrm{P}$ & W \\
\hline 3 & V & S & $S$ & $\mathrm{~V}$ & $\mathrm{C}$ & V & $\mathrm{C}$ & V & $\mathrm{C}$ & $\mathrm{P}$ & $\mathrm{L}$ & $\mathrm{L}$ & $\mathrm{P}$ & W & $\mathrm{P}$ & W & $\mathrm{P}$ & $\mathrm{L}$ \\
\hline 4 & $\mathrm{~V}$ & $\mathrm{C}$ & $S$ & $\mathrm{~V}$ & $\mathrm{C}$ & V & $\mathrm{S}$ & C & $\mathrm{V}$ & $\mathrm{P}$ & W & $\mathrm{L}$ & $\mathrm{P}$ & W & $\mathrm{P}$ & $\mathrm{L}$ & W & $\mathrm{L}$ \\
\hline 5 & $\mathrm{C}$ & $\mathrm{S}$ & C & V & $\mathrm{V}$ & V & $\mathrm{C}$ & $S$ & $\mathrm{~V}$ & W & $\mathrm{L}$ & W & $\mathrm{P}$ & $\mathrm{P}$ & $\mathrm{P}$ & $\mathrm{W}$ & $\mathrm{L}$ & W \\
\hline 6 & $\mathrm{C}$ & V & $S$ & S & $\mathrm{S}$ & $\mathrm{C}$ & $\mathrm{S}$ & V & V & W & $\mathrm{P}$ & $\mathrm{L}$ & $\mathrm{L}$ & $\mathrm{L}$ & W & $\mathrm{L}$ & $\mathrm{P}$ & $\mathrm{L}$ \\
\hline 7 & $\mathrm{~S}$ & $\mathrm{~V}$ & C & $\mathrm{C}$ & $\mathrm{V}$ & $S$ & $\mathrm{~S}$ & C & $\mathrm{C}$ & $\mathrm{L}$ & $\mathrm{P}$ & W & W & $\mathrm{P}$ & $\mathrm{L}$ & $\mathrm{L}$ & W & W \\
\hline 8 & V & $\mathrm{S}$ & V & $\mathrm{C}$ & $\mathrm{S}$ & $S$ & $\mathrm{C}$ & V & S & $\mathrm{P}$ & $\mathrm{L}$ & $\mathrm{P}$ & W & $\mathrm{L}$ & $\mathrm{L}$ & W & $\mathrm{P}$ & $\mathrm{P}$ \\
\hline 9 & $\mathrm{~S}$ & $\mathrm{~V}$ & $S$ & $\mathrm{C}$ & $\mathrm{V}$ & $S$ & $\mathrm{C}$ & C & $\mathrm{S}$ & $\mathrm{L}$ & $\mathrm{P}$ & $\mathrm{L}$ & W & $\mathrm{P}$ & $\mathrm{L}$ & $\mathrm{W}$ & W & $\mathrm{L}$ \\
\hline 10 & $\mathrm{~S}$ & $\mathrm{C}$ & V & $\mathrm{S}$ & $\mathrm{V}$ & C & $\mathrm{V}$ & V & $\mathrm{C}$ & $\mathrm{L}$ & W & $\mathrm{P}$ & $\mathrm{L}$ & $\mathrm{P}$ & W & $\mathrm{P}$ & $\mathrm{P}$ & $\mathrm{P}$ \\
\hline 11 & $\mathrm{C}$ & $\mathrm{V}$ & $\mathrm{S}$ & $\mathrm{C}$ & $\mathrm{S}$ & $S$ & $\mathrm{~V}$ & $\mathrm{C}$ & $\mathrm{S}$ & $\mathrm{W}$ & $\mathrm{P}$ & $\mathrm{L}$ & W & $\mathrm{L}$ & $\mathrm{L}$ & $\mathrm{P}$ & W & $\mathrm{L}$ \\
\hline 12 & $\mathrm{C}$ & $\mathrm{C}$ & V & $\mathrm{S}$ & $\mathrm{S}$ & $\mathrm{C}$ & V & $S$ & $\mathrm{~S}$ & W & W & $\mathrm{P}$ & $\mathrm{L}$ & $\mathrm{L}$ & W & $P$ & $\mathrm{~L}$ & $\mathrm{P}$ \\
\hline 13 & $\mathrm{C}$ & $\mathrm{V}$ & $S$ & $\mathrm{~S}$ & $\mathrm{C}$ & V & $\mathrm{V}$ & C & $\mathrm{V}$ & W & $\mathrm{P}$ & $\mathrm{L}$ & $\mathrm{L}$ & W & $\mathrm{P}$ & $\mathrm{P}$ & $\mathrm{W}$ & $\mathrm{L}$ \\
\hline 14 & $\mathrm{C}$ & $\mathrm{S}$ & V & $\mathrm{C}$ & $\mathrm{S}$ & V & $\mathrm{C}$ & $S$ & $\mathrm{~S}$ & W & $\mathrm{L}$ & $\mathrm{P}$ & W & $\mathrm{L}$ & $\mathrm{P}$ & $\mathrm{W}$ & $\mathrm{L}$ & $\mathrm{P}$ \\
\hline 15 & $\mathrm{C}$ & $\mathrm{V}$ & $S$ & $\mathrm{C}$ & $\mathrm{V}$ & C & $\mathrm{S}$ & S & $S$ & W & $\mathrm{P}$ & $\mathrm{L}$ & W & $\mathrm{P}$ & W & $\mathrm{L}$ & $\mathrm{L}$ & $\mathrm{L}$ \\
\hline 16 & $\mathrm{~V}$ & $\mathrm{~S}$ & C & $\mathrm{S}$ & $\mathrm{S}$ & $\mathrm{C}$ & $\mathrm{V}$ & $S$ & $\mathrm{~S}$ & $\mathrm{P}$ & $\mathrm{L}$ & W & $\mathrm{L}$ & $\mathrm{L}$ & W & $\mathrm{P}$ & $\mathrm{L}$ & W \\
\hline 17 & $\mathrm{C}$ & $\mathrm{S}$ & V & S & $\mathrm{C}$ & V & $\mathrm{S}$ & C & $\mathrm{V}$ & W & $\mathrm{L}$ & $\mathrm{P}$ & $\mathrm{L}$ & W & $\mathrm{P}$ & $\mathrm{L}$ & $\mathrm{W}$ & $\mathrm{P}$ \\
\hline 18 & $\mathrm{~S}$ & $\mathrm{C}$ & V & S & $\mathrm{V}$ & $S$ & $\mathrm{C}$ & V & $\mathrm{C}$ & $\mathrm{L}$ & W & $\mathrm{P}$ & $\mathrm{L}$ & $\mathrm{P}$ & $\mathrm{L}$ & W & $\mathrm{P}$ & $\mathrm{P}$ \\
\hline 19 & $\mathrm{~S}$ & $\mathrm{~V}$ & C & $\mathrm{V}$ & $\mathrm{C}$ & S & $\mathrm{V}$ & S & $\mathrm{C}$ & $\mathrm{L}$ & $\mathrm{P}$ & W & $\mathrm{P}$ & W & $\mathrm{L}$ & $\mathrm{P}$ & $\mathrm{L}$ & W \\
\hline 20 & $\mathrm{~S}$ & $\mathrm{C}$ & $\mathrm{S}$ & $\mathrm{C}$ & $\mathrm{V}$ & S & $\mathrm{C}$ & V & $\mathrm{V}$ & $\mathrm{L}$ & W & $\mathrm{L}$ & W & $\mathrm{P}$ & $\mathrm{L}$ & $\mathrm{W}$ & $\mathrm{P}$ & $\mathrm{L}$ \\
\hline 21 & $\mathrm{~V}$ & $\mathrm{~V}$ & C & $\mathrm{S}$ & $\mathrm{S}$ & C & $\mathrm{V}$ & C & $\mathrm{V}$ & $\mathrm{P}$ & $\mathrm{P}$ & W & $\mathrm{L}$ & $\mathrm{L}$ & W & $\mathrm{P}$ & $\mathrm{W}$ & W \\
\hline 22 & $\mathrm{~S}$ & $\mathrm{C}$ & V & $\mathrm{V}$ & $\mathrm{C}$ & $S$ & $\mathrm{C}$ & $S$ & $\mathrm{~S}$ & $\mathrm{~L}$ & W & $\mathrm{P}$ & $\mathrm{P}$ & W & $\mathrm{L}$ & W & $\mathrm{L}$ & $\mathrm{P}$ \\
\hline 23 & $\mathrm{~V}$ & $\mathrm{C}$ & V & $\mathrm{C}$ & $\mathrm{S}$ & C & $\mathrm{V}$ & $S$ & $\mathrm{~V}$ & $\mathrm{P}$ & W & $\mathrm{P}$ & $\mathrm{W}$ & $\mathrm{L}$ & W & $\mathrm{P}$ & $\mathrm{L}$ & $\mathrm{P}$ \\
\hline 24 & V & $\mathrm{S}$ & $\mathrm{C}$ & $\mathrm{V}$ & V & C & $\mathrm{S}$ & V & $\mathrm{C}$ & $\mathrm{P}$ & $\mathrm{L}$ & W & $\mathrm{P}$ & $\mathrm{P}$ & W & $\mathrm{L}$ & $\mathrm{P}$ & W \\
\hline 25 & $\mathrm{C}$ & $\mathrm{C}$ & $\mathrm{C}$ & $\mathrm{C}$ & $\mathrm{C}$ & C & $\mathrm{C}$ & C & $\mathrm{C}$ & W & $\mathrm{L}$ & $\mathrm{L}$ & $\mathrm{P}$ & W & $\mathrm{P}$ & $\mathrm{W}$ & $\mathrm{P}$ & $\mathrm{L}$ \\
\hline 26 & $\mathrm{~V}$ & $\mathrm{~V}$ & $\mathrm{~V}$ & $\mathrm{~V}$ & $\mathrm{~V}$ & V & $\mathrm{V}$ & V & $\mathrm{C}$ & $\mathrm{P}$ & W & $\mathrm{P}$ & W & $\mathrm{L}$ & $\mathrm{L}$ & $\mathrm{P}$ & $\mathrm{L}$ & $\mathrm{P}$ \\
\hline 27 & $\mathrm{~S}$ & $\mathrm{~S}$ & $\mathrm{~S}$ & $\mathrm{~S}$ & $\mathrm{~S}$ & $S$ & $\mathrm{~S}$ & $S$ & $\mathrm{~S}$ & $\mathrm{~L}$ & $\mathrm{P}$ & W & $\mathrm{L}$ & $\mathrm{P}$ & W & $\mathrm{L}$ & W & W \\
\hline 28 & $\mathrm{C}$ & $\mathrm{C}$ & $\mathrm{C}$ & $\mathrm{C}$ & $\mathrm{C}$ & $\mathrm{C}$ & $\mathrm{C}$ & C & $\mathrm{S}$ & $\mathrm{P}$ & $\mathrm{P}$ & W & $\mathrm{L}$ & $\mathrm{L}$ & W & $\mathrm{W}$ & $\mathrm{P}$ & W \\
\hline 29 & $\mathrm{~V}$ & $\mathrm{~V}$ & $\mathrm{~V}$ & $\mathrm{~V}$ & $\mathrm{~V}$ & V & $\mathrm{V}$ & V & $\mathrm{V}$ & W & $\mathrm{L}$ & $\mathrm{L}$ & $\mathrm{P}$ & W & $\mathrm{P}$ & $\mathrm{L}$ & W & $\mathrm{L}$ \\
\hline 30 & $\mathrm{~S}$ & $\mathrm{~S}$ & $\mathrm{~S}$ & $S$ & $\mathrm{~S}$ & $\mathrm{~S}$ & $\mathrm{~S}$ & $\mathrm{~S}$ & V & $\mathrm{L}$ & W & $\mathrm{P}$ & W & $\mathrm{P}$ & $\mathrm{L}$ & $\mathrm{P}$ & $\mathrm{L}$ & $\mathrm{P}$ \\
\hline $\begin{array}{l}\text { (b) The } \\
\text { (c) The }\end{array}$ & & tio & & & & $\mathrm{ce}$ & & $\mathrm{P}$ & & & & & & & & & & \\
\hline
\end{tabular}


Although the bench, row on a bench, and column on a bench are not variables of direct interest for the testing, it is a good idea to account for possible effects of such nuisance variables in the experimental design. Doing so protects against the possibility that there may be position effects (e.g., in spore deposition or in sample collection) over the benches and positions. Such bench or position effects would otherwise be confounded with the effects of surface material (a test factor), which is undesirable.

Figure 6.1 also displays the six locations on Bench 3 that were used for negative control tests. These locations had two uncontaminated coupons of each of the three surface materials in Block 1 (stainless steel, vinyl tile, and ceramic tile) and Block 2 (plastic, painted wood paneling, and faux leather). In summary, the experimental design for the VSPWG sponge-wipe study is documented in Table 6.1, Table 6.2, and Figure 6.1. 


\subsection{Gap Coverage, Advantages, and Disadvantages of this Study}

Many previous chamber and laboratory studies on the performance of sampling methods for surfaces contaminated by BA or surrogates have been conducted and were summarized by Piepel et al. (2010). Several gaps were identified in these previous studies, and the current sponge-wipe study was planned to fill some of the gaps. The main gaps identified were 1) lack of results quantifying FNR and RE as functions of contaminant concentration, surface material, sample collection and analysis methods, and other factors, 2) lack of studies to investigate and quantify the effects of sample storage and transportation conditions on the performance results of sampling and analysis methods, and 3) failure of previous studies to capture all of the sources of uncertainty affecting performance results of sampling and analysis methods under various conditions. Regarding the last gap, many of the studies investigated only shortterm, within-test uncertainties (repeatability) and did not investigate run-to-run or lab-to-lab uncertainties (reproducibility). Hence, the estimated uncertainties of performance measures reported in those studies can be expected to underestimate the total uncertainty.

Given the resources available for the sponge-wipe study, it was not possible to fill all of the gaps identified by Piepel et al. (2010). The advantages and disadvantages of the sponge-wipe-study experimental design presented in this report are discussed in the following bullets.

\section{Advantages}

- The study provides for developing FNR-concentration and RE-concentration equations and corresponding uncertainty expressions for each of six surface materials tested: three in Block 1 (stainless steel, vinyl tile, and ceramic tile) and three in Block 2 (plastic, painted wood paneling, and faux leather). These equations and expressions will provide for predicting the FNR, RE, and their uncertainties for any concentration within the range tested. Failure to develop FNR-concentration and RE-concentration equations was the largest gap identified by Piepel et al. (2010) in their summary of previous chamber and laboratory studies for BA (or surrogates) contamination.

- Tests were conducted using sponge-wipe sample collection, preparation, extraction, and analysis methods according to procedures developed by the CDC. Thus, what are expected to be validated methods associated with sponge-wipe surface sampling were used to achieve the goals of the study.

- Positive-control (reference) samples will provide for estimating the contaminant concentration level on each test coupon. The concentration in the positive-control sample associated with each test coupon will be used to calculate REs and will also serve as the concentration value in fitting FNRconcentration and RE-concentration equations. The control sample concentration values will also be used to identify any possible variations in concentrations across test coupons within a test run because of time trend, bench, bench position, and/or other effects.

- Technicians who performed the sample collection, processing, and counting stages of testing were varied in a balanced, randomized way during testing. This avoided confounding their effects, if any, with the effects of surface material and contaminant concentration.

- Performance data for the sponge-wipe sample collection, extraction, and analysis methods recommended by CDC were obtained for a BA surrogate (Bacillus atrophaeus) using wet deposition on test coupons. The performance data for the concentrations used in this study will be compared to 
the lowest concentration data from preliminary dry aerosol tests. The goal of this comparison is to provide a basis for predicting the performance of the sponge-wipe method for lower concentrations of dry-aerosol-deposited contaminant than were able to be tested.

\section{Disadvantages}

- Only the sponge-wipe sample collection method was tested in this laboratory study. It is envisioned that swab and vacuum sampling methods can be addressed in future similar studies.

- Preparation and extraction methods can have a significant effect on sampling performance (e.g., RE and FNR), but those factors were not varied in this study. In this study, the preparation and extraction methods recommended by CDC and used in Laboratory Response Network laboratories were used. Other preparation and extraction methods have been investigated and documented in the literature, and additional studies varying these factors could be performed in the future if necessary.

- The study did not consider the effects of storage and transportation factors on sponge-wipe sampling performance. Insufficient information on these factors was identified as a gap by Piepel et al. (2010). CDC has recently completed a storage/transportation study, and it is recommended that the results of that study be evaluated to decide whether additional studies are needed.

- Only the SNL laboratory was used, and therefore lab-to-lab variation was not investigated or quantified. Three SNL technicians performed the test steps in the 16 test runs. However, given the small number of technicians, their schedules, and the number of steps in the work, it was not possible to assign technicians so as to capture personnel-related sources of reproducibility uncertainty. Instead, technicians were assigned in a balanced, randomized way to the test steps to avoid confounding any possible technician effects with effects of the primary test variables (concentration and surface material).

- Run-to-run uncertainty will not be quantifiable because of the decision to test three different materials in Block 2 rather than replicating the Block 1 tests in Block 2. The advantage of gathering performance data on six surface materials with a wider range of surface characteristics than for the initial three materials was considered to out-weigh the disadvantage of not being able to quantify runto-run uncertainty.

- The study was initially planned with dry aerosol deposition of the contaminant on test coupons in a chamber. However, preliminary tests showed that the sponge-wipe method was efficient enough that no false negatives were obtained at the lowest surface concentrations of contaminant that could be reliably achieved by dry-aerosol deposition. Hence, it was necessary to change the study to using wet deposition of the contaminant. This allowed achieving the lower surface concentrations of the contaminant needed to obtain a range of FNR values for different surface materials when using the sponge-wipe method.

These advantages and disadvantages should be kept in mind when 1) assessing and drawing conclusions from the results of this sponge-wipe study and 2) planning any future chamber or laboratory studies. 


\subsection{Planned Data Analyses}

An important part of designing an experiment is planning the future data analyses to be performed so that the experimental data will adequately support those analyses. In general, it is envisioned that the sponge-wipe study will support completing all of the entries in Table 1 of Piepel et al. (2010), with the exceptions of lab-to-lab uncertainty (since only one laboratory will be used) and run-to-run uncertainty (since it was decided to test three different materials in Block 2). For convenience, that table is reproduced in this report as Table 8.1.

Focusing on the most important items, the experimental design for the sponge-wipe study presented in this report will support:

- Estimating the FNR and the corresponding uncertainty for each combination of contaminant concentration and surface material.

- Estimating the surface concentrations (e.g., colony forming units $[\mathrm{CFU}] / \mathrm{cm}^{2}$ ) and their uncertainties (e.g., percent relative standard deviation [\%RSD]) of the contaminant for each combination of concentration and surface material.

- Estimating RE (\%) and their uncertainties (\%RSD) for each combination of contaminant concentration and surface material.

- Fitting FNR-concentration and RE-concentration equations for each of the six surface materials, assessing goodness-of-fit of the equations, and quantifying the uncertainty in PCD/FNR and RE predictions made with the fitted equations.

Using results of the sponge-wipe study, it will be possible to calculate various kinds of "limits of detection" for the six non-porous materials using the CDC-validated, sponge-wipe sampling and analysis methods. The limit of detection (LOD) is controversial because different researchers define and calculate it in different ways, which is often inadequately discussed. The definitions and methods we will use to calculate LODs will be discussed in a separate document on the results and data analyses of the study. Section 6 of this document describes the experimental design with a split-plot structure in which contaminant concentrations are the WP treatments and surface materials are the SP treatments. Because it was decided to test three different surface materials in Block 2 than were tested in Block 1, the experimental design no longer involves testing all eight of the nominal contaminant concentrations twice. However, one test run in each of Block 1 and Block 2 was replicated (see Table 6.1). Such "whole-plot" replicates provide for estimating the WP uncertainty, although fitting FNR-concentration equations with a few less parameters than the number of concentration levels will also provide for estimating the WP uncertainty. Replicate coupons of each surface material within each test run will provide for estimating SP uncertainty. Some data analyses (such as fitting RE-concentration and FNR-concentration equations) will not require the more complicated split-plot data-analysis methods because those data analyses will be performed separately for each surface material. Hence, the minimal number of WP replicates will not affect those data analyses. However, if attempts are made to develop RE-concentration and FNRconcentration equations applicable to a range of surface materials (e.g., possibly by using surface characteristics as predictor variables), then split-plot data-analysis methods will be needed. 
Table 8.1. Information Summarized by Piepel et al. (2010) in Their Literature Review of Previous Chamber and Laboratory Studies for Sampling and Analyzing Contaminated Surfaces

\begin{tabular}{|c|c|}
\hline \multicolumn{2}{|l|}{ Study Characteristics } \\
\hline Row Number & Continuous number to aid in referring to specific rows of a table \\
\hline Study & Publication used to summarize the study \\
\hline Test \# & $\begin{array}{l}\text { A number of the form } \mathrm{x} . \mathrm{y} \text { where } \mathrm{x} \text { is } 1,2,3, \ldots \text { for each study, and } \mathrm{y}=1,2,3, \ldots \text { for the tests } \\
\text { within a study }\end{array}$ \\
\hline $\begin{array}{l}\text { Swab/Wipe/Vacuum } \\
\text { Characteristics }\end{array}$ & Characteristics or material of sampling method \\
\hline Wetting Agent & Liquid, if any, used to wet or pre-moisten the sampling material (e.g., swab or wipe) \\
\hline Surface Tested & Material type of surface sampled \\
\hline Nature of Contaminant & Bacillus anthracis or related surrogate \\
\hline Contaminant Amount & Amount or concentration of contaminant \\
\hline Contaminant Deposition & How contaminant was deposited on the test materials \\
\hline Transport / Storage Conditions & Transportation or storage conditions for samples before analysis \\
\hline Preparation/Extraction Method & Method used to prepare a sample and extract the contaminant \\
\hline Analytical Method & Method used to analyze prepared samples \\
\hline \multicolumn{2}{|l|}{ Study Results } \\
\hline \multicolumn{2}{|r|}{ Study Results - Mean and SDs } \\
\hline \# Test Runs & $\begin{array}{l}\text { The number of test runs (set up and performed separately at different times). These may be } \\
\text { thought of as "blocks" in statistical experimental design terminology. }\end{array}$ \\
\hline Total \# Test Samples & $\begin{array}{l}\text { Total number of samples used to calculate mean and standard deviations, as well as recovery } \\
\text { efficiency }\end{array}$ \\
\hline Mean $\left(\mathrm{CFU} / \mathrm{cm}^{2}\right)$ & Average contamination over the number of samples \\
\hline Lab \%RSD & $\begin{array}{l}\text { Lab-to-lab percent relative standard deviation, which includes the variation from preparing the } \\
\text { samples, extraction, and analysis }\end{array}$ \\
\hline Run \%RSD & Percent relative standard deviation from replicate runs of a test performed at different times \\
\hline Sample Within Run \%RSD & Percent relative standard deviation from replicate tests performed at the same time (in one run) \\
\hline Within Sample \%RSD & Percent relative standard deviation from split preparations and/or analyses from a given sample \\
\hline Total \%RSD & Total percent relative standard deviation including all of the preceding sources of variation \\
\hline \multicolumn{2}{|r|}{ Recovery Efficiency (RE) - Mean and \%RSDs } \\
\hline RE Mean $(\%)$ & Mean recovery efficiency over the number of test samples \\
\hline RE Lab \%RSD & Lab-to-lab percent relative standard deviation of RE \\
\hline RE Run \%RSD & Run percent relative standard deviation of RE \\
\hline RE Sample Within Run \%RSD & Sample-within-run percent relative standard deviation of RE \\
\hline RE Total \%RSD & Total percent relative standard deviation of RE \\
\hline \multicolumn{2}{|r|}{ LOD $($ CFU/cm²) \& Rates } \\
\hline Definition of LOD & How the limit of detection (LOD) is defined \\
\hline \# of Data Points & Number of data points used to calculate the LOD \\
\hline Positive Result Definition (CFU) & How a positive result (detection) is defined (e.g., CFU $\geq 1$ ) \\
\hline $\mathrm{LOD}\left(\mathrm{CFU} / \mathrm{cm}^{2}\right)$ & Value of the limit of detection \\
\hline LOD SD or $95 \% \mathrm{CI}\left(\mathrm{CFU} / \mathrm{cm}^{2}\right)$ & Standard deviation or $95 \%$ confidence interval for the LOD \\
\hline $\begin{array}{l}\text { Probability Curve for Detecting a } \\
\text { Positive }\end{array}$ & Method used to develop a probability curve for correctly detecting contamination \\
\hline False Negative Rate & $\begin{array}{l}\text { False negative rate based on controlled tests where the sampled surface was known to be } \\
\text { contaminated but yielded a negative result }\end{array}$ \\
\hline False Positive Rate & $\begin{array}{l}\text { False positive rate based on controlled tests where the sampled surface was known to be } \\
\text { uncontaminated but yielded a positive result }\end{array}$ \\
\hline Comments & Explanatory comments about the study or results \\
\hline
\end{tabular}




\subsection{Recommendations for Future Studies}

As discussed previously, the sponge-wipe study in this report only addresses some of the gaps in previous chamber and laboratory studies identified by Piepel et al. (2010). Hence, additional evaluations of previous studies and new experimental studies are recommended to address the following topics.

- Quantifying False Negative Rates for Swab and Vacuum Sampling Methods: Studies similar to the sponge-wipe study discussed in this report should be performed for swab and vacuum sampling and analysis methods recommended by the CDC. Other wipe, swab, or vacuum methods that are likely to be used should also be investigated (see the discussion in the following bullet). Piepel et al. (2010) summarized literature results from 4 vacuum studies (noting that more were needed) and 14 swab studies. However, none of these studies investigated a sufficient number of concentrations at low enough concentration levels to quantify the FNR as a function of concentration and any other affecting variables. Quantifying the FNR is critical to being able to calculate the confidence in detection and clearance decisions when all samples yield negative results.

- Quantifying Performance of Different Methods: The CDC has performed validation studies for the sponge-wipe method, a specific swab method, and corresponding recommended extraction and analysis methods. A similar study for CDC-validated vacuum sampling, extraction, and analysis methods is planned. However, it is reasonable to expect that biological contamination events in various parts of the United States may result in wipe, swab, and vacuum sample collection methods that differ from methods recommended by the CDC, as well as different storage/transportation, extraction, and analysis methods. Previous studies summarized by Piepel et al. (2010) showed that different sample collection methods and different extraction methods can have significantly different performance results. Hence, it would be prudent to quantify the FNR performance of the two or three most likely to be used swab, wipe, and vacuum sample collection methods, transportation/storage methods, extraction methods, and analysis methods. We recommend that 1) the two or three most likely to be used methods of each type be identified and 2) the existing literature data summarized by Piepel et al. (2010) be evaluated to see how well the performance of those most likely methods has been investigated. If there are gaps, then additional experimental studies may be needed.

- Reproducibility Uncertainty: The majority of previous chamber and laboratory studies only quantified within-laboratory uncertainty (Piepel et al. 2010) and sometimes only short-term, within-laboratory uncertainty. Lab-to-lab uncertainty and other sources of reproducibility uncertainty (e.g., test personnel, instruments, etc.) need to be quantified as functions of any affecting variables (e.g., contaminant concentration). It was not possible to include these features in the sponge-wipe study discussed in this report, and hence it is recommended that reproducibility uncertainty be quantified in future experimental studies for the sponge-wipe method as well as in any future swab and vacuum studies.

- Transportation and Storage Effects: The Almeida et al. (2008) study and the recent CDC study of storage/transportation effects on sample results (journal article being written) should be evaluated to determine if additional studies are needed to quantify storage and transportation effects as functions of any affecting variables (e.g., contaminant concentration). 


\subsection{References}

Almeida JL, B Harper, and KD Cole. 2008. "Bacillus anthracis Spore Suspensions: Determination of Stability and Comparison of Enumeration Techniques." Journal of Applied Microbiology 104:14421448.

Atkinson AC, AN Donev, and RD Tobias. 2007. Optimum Experimental Designs, with SAS, Oxford University Press, New York, NY.

Estill CF, PA Baron, J Beard, MJ Hein, LD Larsen, L Rose, FW Schaefer III, J Noble-Wang, L Hodges, HDA Lindquist, GJ Deye, and MJ Arduino. 2009. "Recovery Efficiency and Limit of Detection of Aerosolized Bacillus anthracis Sterne from Environmental Surface Samples." Applied and Environmental Microbiology 75:4297-4306.

Government Accountability Office (GAO). 2005a. Anthrax Detection: Agencies Need to Validate Sampling Activities in Order to Increase Confidence in Negative Results (Report to the Chairman, Subcommittee on National Security, Emerging Threats, and International Relations, House Committee on Government Reform, House of Representatives), GAO-05-251, U.S. Government Accountability Office, Washington, DC.

Government Accountability Office (GAO). 2005b. Anthrax Detection: Agencies Need to Validate Sampling Activities in Order to Increase Confidence in Negative Results, (Testimony before the Chairman, Subcommittee on National Security, Emerging Threats, and International Relations, House Committee on Government Reform, House of Representatives), GAO-05-493T, U.S. Government Accountability Office, Washington, DC.

Hallas K and R Shaw. 2006. Evaluation of the Kirchberg Rolling Slider and SlipAlert Slip Resistance Meters. HSL/2006/65, Health \& Safety Laboratory, Harpur Hill, Buxton, Derbyshire, UK.

Myers RH and DC Montgomery. 1995. Response Surface Methodology: Process and Product Optimization Using Designed Experiments. John Wiley and Sons Inc., New York.

Piepel GF, BG Amidan, and JB Morrow. 2010. Summary of Previous Chamber and Controlled Anthrax Studies and Recommendations for Possible Additional Studies by the VSPWG. PNNL-SA-69338, Rev. 1, Pacific Northwest National Laboratory, Richland, Washington.

SAS. 2008. SAS Version 9.2, SAS Institute, Inc, Cary, NC.

Shellenberger K and BE Logan. 2002. "Effect of Molecular Scale Roughness of Glass Beads on Colloidal and Bacterial Deposition.” Environmental Science and Technology 36:184-189.

Steel RGD and JH Torrie. 1960. Principles and Procedures of Statistics, McGraw-Hill Book Company, Inc., New York. 


\section{Distribution}

No. of

Copies

\section{External Distribution}

9 Department of Homeland Security John Bridges (JHBridges@vzw.blackberry.net) Lance Brooks (lance.brooks@dhs.gov) Bert Coursey (bert.coursey@dhs.gov) Elizabeth George (elizabeth.george@dhs.gov) Randy Long (randolph.long@dhs.gov)

Kristin Pasternak (kristin.pasternak@associates.dhs.gov) Segaran Pillai (segaran.pillai@dhs.gov) Chris Russell (Christopher.E.Russell@dhs.gov) Kelli Thompson (Kelli.L.Thompson@dhs.gov)

10 Environmental Protection Agency Michelle Burgess (burgess.michele @epa.gov) Erica Canzler (canzler.erica@epa.gov) Schatzi Fitz-James (fitz-james.schatzi@epa.gov) Romy Lee (lee.romy@epa.gov) Dino Mattorano (mattorano.dino@epa.gov) Marissa Mullins (mullins.marissa@epa.gov) Tonya Nichols (nichols.tonya@epamail.epa.gov) Sarah Perkins (Perkins.Sarah@epamail.epa.gov) Shawn Ryan (ryan.shawn@epa.gov) Sanjiv Shah (shah.sanjiv@epa.gov)

3 Sandia National Laboratories Wayne Einfeld (weinfel@sandia.gov) Bob Knowlton (rgknowl@sandia.gov) Paula Krauter (pkraute@sandia.gov)

3 National Institute of Standards \& Technology Stuart Dols (wsdols@ nist.gov) Jayne Morrow (jayne.morrow@nist.gov) Andrew Persily (andrew.persily@ nist.gov)

1 Johns Hopkins University Applied Physics Laboratory Eric Van Gieson (eric.van.gieson@jhuapl.edu)
No. of

$\underline{\text { Copies }}$

9 Center for Disease Control and Protection Matthew Arduino (marduino@cdc.gov)

Lisa Delaney (ldelaney1@cdc.gov)

Cherie Estill (c14@cdc.gov)

Richard Kellogg (rbk1@cdc.gov)

Ken Martinez (kmartinez@cdc.gov)

Stephen Morse (sam1@cdc.gov)

Laura Rose (lmr8@cdc.gov)

Angela Weber (aweber@cdc.gov)

Betsy Weirich (eweirich@cdc.gov)

4 Federal Bureau of Investigation

Doug Anders (douglas.anders@ic.fbi.gov)

Kristine Beardsley (kristine.beardsley@ic.fbi.gov)

Doug Beecher (douglas.beecher@ic.fbi.gov)

Nick Paquette (nicholas.paquette@ic.fbi.gov)

2 Institute for Defense Analyses

Jeff Grotte (jgrotte@ida.org)

Margaret Hebner (mhebner@ida.org)

3 Homeland Security Institute

Phil Hammar (philip.hammar@hsi.dhs.gov)

Ed Hildebrand (carl.hildebrand@ @si.dhs.gov)

Eric Sylwester (eric.sylwester@hsi.dhs.gov)

2 Department of Defense - Joint Program Executive Office (JPEO)

Emma Wilson (emma.wilson@jpeocbd.osd.mil)

Kevin Smith (kevin.smith@jpeocbd.osd.mil)

\section{Internal Distribution}

Pacific Northwest National Laboratory

Brett Amidan (brett.amidan@pnl.gov)

Brett Matzke (brett.matzke@pnl.gov)

Greg Piepel (greg.piepel@pnl.gov)

Brent Pulsipher (brent.pulsipher@pnl.gov)

Landon Sego (landon.sego@pnl.gov)

Nancy Valentine (nancy.valentine@ pnl.gov)

Information Release 



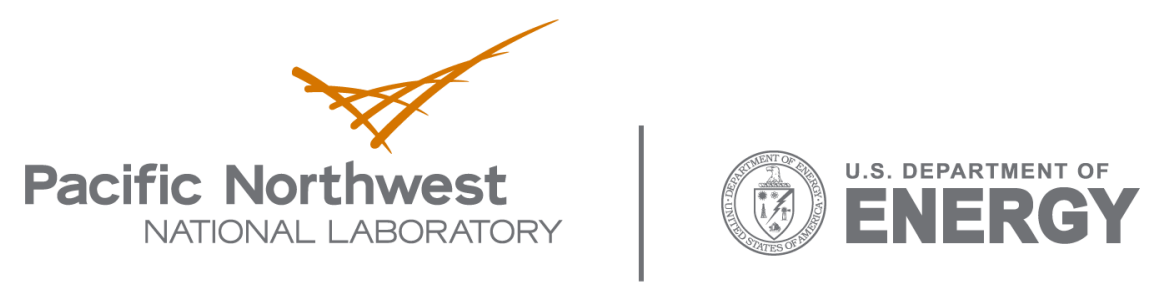

902 Battelle Boulevard

P.O. Box 999

Richland, WA 99352

1-888-375-PNNL (7665)

www.pnl.gov 